\title{
BIOÉTICA E INTERDISCIPLINARIDADE: DIREITOS DE PACIENTES E ACOMPANHANTES NA HOSPITALIZAÇÃO
}

Maria Aparecida Crepaldi ${ }^{1}$

\begin{abstract}
RESUMO: Este trabalho tem como temática principal a bioética aplicada à atuação de profissionais de saúde no contexto hospitalar. Tem como objetivo principal apresentar e discutir aspectos das condutas dos profissionais de saúde junto a pacientes hospitalizados e seus acompanhantes, e de conjunturas da instituição hospitalar, que ferem os aspectos éticos no trato com os usuários. Esta instituição utiliza-se das contribuições da ciência, do saber médico e do avanço da tecnologia para melhorar a assistência destinada à população em geral, mas nem sempre consegue reunir avanço técnico competente e assistência humanizada. Pretende-se, ainda, apresentar e discutir que implicações tem a interdisciplinaridade sobre o campo da bioética no trabalho hospitalar.
\end{abstract}

Palavras chave: bioética, profissionais de saúde, assistência humanizada, interdisciplinaridade.

\section{BIOETHICS AND INTERDISCIPLINARITY: patients and companions rights during hospitalization}

\begin{abstract}
The main theme of this work is the bioethics applied to the performance of health professionals within a hospital. Its objective is to introduce and discuss aspects of health professionals attitudes towards hospitalized patients and their companions ; also the state of affairs of the hospital institution which damages the ethic aspects on the users treatment. This institution uses the contributions of Science in general, of medical knowledge and of the advancement of technology in order to improve the assistence given to the population that makes use of its services. However it is not always possible to join competent technical advance and humanized assistence. This paper intends too to present and discuss the interdisciplinary implications in the field of bioethics in hospital work
\end{abstract}

Key words: Children Hospitalization, companion mothers, families in hospital, parent reception

Temos assistido, ao final deste século, uma preocupação crescente com a moralização da sociedade. Os movimentos sociais que delatam e combatem a corrupção nunca tiveram tanto vigor, e os diversos segmentos da sociedade não toleram mais conviver com a dimensão imoral e desumanizadora da política, da economia e também da ciência.

Segundo Berlinguer (1996) a ciência é o campo, por excelência, em que a dimensão ética tem

\footnotetext{
${ }^{1}$ Endereço para correspondência : Maria Aparecida Crepaldi, Departamento de Psicologia, CFH, Universidade Federal de Santa Catarina, Campus Universitário, Bairro Trindade, CEP 88900000,E-mail crepaldi@cfh.ufsc.br
}

Paidéia, FFCLRP-USP, Rib. Preto, junho/99. ressurgido com força total nos últimos anos.

Como exemplo desta tendência temos testemunhado o surgimento de comitês de ética por toda parte, que examinam projetos de pesquisa e intervenção, nas universidades, empresas, escolas e hospitais.

Esta preocupação com a ciência em todas as suas dimensões abre uma discussão fundamental que leva em conta o "conflito de fundo entre desenvolvimento científico e tecnolbgico e o autêntico crescimento humano" (Berlinguer, 1996, p. 14).

Neste sentido este artigo tem como temática principal a bioética no trabalho hospitalar, que, por 
sua vez, utiliza-se das contribuições da ciência, do saber médico e do avanço da tecnologia para melhorar a assistência. Pretende-se, ainda, apresentar e discutir aspectos das condutas dos profissionais de saúde, junto a pacientes hospitalizados e seus acompanhantes, e de conjunturas da instituição hospitalar, que ferem os aspectos éticos no trato com os usuários, e que implicações tem a interdisciplinaridade sobre este campo.

\section{A História do Hospital Moderno}

Em se tratando de pessoas doentes e hospitalizadas, o tema da bioética nos remete diretamente à história da organização hospitalar como campo de práticas de assistência.

Até o final do século XVIII, o hospital não era um instrumento terapêutico, como mostra Foucault (1985), mas sim um lugar destinado à exclusão, pois confinava no mesmo espaço todos os segmentos da população considerados nocivos para a sociedade e que, portanto, mereciam viver à margem do convívio social, como loucos, prostitutas, pobres, além de pessoas doentes.

Pitta (1999) refere que no hospital antigo existia sim a idéia de cura, mas esta tinha um âmbito limitado, já que a medicina era uma prática não hospitalar e o contexto hospitalar não curava tão bem como deveria fazê-lo.

Foucault (1985) rechaça a idéia de que o hospital fosse um instrumento destinado a curar, mas sim uma instituição de assistência aos pobres, e sobretudo ao pobre que está morrendo, que deve ser assistido material e espiritualmente. Para lá iam pessoas que estavam à morte. Caracterizava-se, então, segundo o autor, como um "morredouro", lugar de práticas religiosas que visavam a salvação de almas.

Com o advento da medicina higiênica, pautada nas descobertas de Pasteur, e a encargo de médicos europeus a mando de autoridades de Estado, o hospital é transformado em um espaço eminentemente médico e a medicina encarrega-se da anulação de seus efeitos nocivos sobre a cidade, sobre a comunidade, a partir do que Foucault (1985) chama de tecnologia disciplinar. Assim medicina e disciplina juntaram-se para dar origem ao hospital médico, que se configura como lugar de formação médica, um dispositivo essencialmente de cura, onde a morte passa a ser negada, escamoteada. Neste novo espaço, onde a eficiência técnica é de extrema relevância, a morte passa a ser vista como o fracasso da instituição médica.

O hospital moderno, tecnologicamente avançado, passa a privilegiar a disciplinarização rígida dos espaços, separando doentes e doenças, em nome da assepsia e da preservação dos corpos. Busca agora a terapêutica, com vigor e afinco cada vez mais diferenciados, negligenciando então, quase que rotineiramente, o caráter humano dos sujeitos que necessitam de cuidados em função de estarem acometidos por uma doença.

\section{A Despersonalização da Clientela}

Adentrando o hospital, o homem sofre o que Goffman (1961) chama de "processo de despojamento", para descrever os procedimentos do processo de admissão da pessoa diagnosticada como doente mental, que necessita de assistência na instituição manicomial, ou seja, é destituído de suas roupas, seus pertences, enfim de sua identidade, portanto dos atributos através dos quais o indivíduo se identifica, reconhece-se como pessoa.

No hospital geral o processo de admissão é análogo, a pessoa doente não pode levar para o hospital as marcas de sua identidade, seus objetos, sua família, enfim sua pessoa. Transforma-se, então, em uma doença, em um órgão doente, em um número de leito. Em função da cura e da conservação do corpo, perde-se a dimensão de totalidade do homem e sua condição de ser humano, para tornar-se um corpo passível de ser curado. Tratando o homem desta forma o hospital perde seu caráter acolhedor e hospitaleiro, que lhe conferia o dispositivo religioso.

Constata-se que no hospital moderno há uma dicotomia entre avanço técnico-científico e a dimensão humanizadora da assistência, como se ambos tivessem que caminhar separadamente.

Quando se discutem práticas humanizadas na assistência à saúde, não se pode correr o risco de cair no obscurantismo científico, au se defender uma atuação que leve em conta o acolhimento, a intimidade e a naturalidade nas relações de ajuda. Tais práticas, que resgatam a dimensão humana na assis- 
tência, devem se efetivar em um contexto de eficiência técnica e especializada.

Para Berlinguer (1996) não se pode correr o risco de que por meio da crítica à medicalização da sociedade se coloque em xeque toda a medicina moderna e a ciência. Não é esta nossa intenção, trata-se de encontrar caminhos que nos possam levar a fazer associações bem sucedidas entre um atendimento cientificamente correto e altamente humanizado.

Embora a temática da humanização não seja um assunto novo para a maioria dos que se interessam pelo contexto hospitalar, seja como campo de práticas, ou campo de pesquisa, na área das ciências da saúde e humanas é fundamental ressaltar que não se trata de um tema esgotado, pois apesar de ter sido mencionado reiteradas vezes, as práticas continuam submetendo as pessoas doentes e seus familiares a situações de constrangimento $e$ desconsideração, esquecendo-se do que deveria ser o objetivo primeiro da função hospitalar, qual seja, resgatar a saúde e dignidade dos cidadãos. Este quadro contradiz, de certa forma, com uma característica que sempre norteou a prática médica, até o final século XIX, ou seja, a de ser essencialmente humanizada, tendo o médico como uma figura de apoio e de confiança para sua clientela.

\section{Práticas do Contexto Hospitalar}

Como consequiência do que fora trazido até aqui, encontramos no contexto hospitalar a adoção de práticas de cuidados que podem ser consideradas pouco éticas, que em geral não são percebidas como tal pela equipe de saúde, que como agente das rotinas, regras e normas que conduzem os serviços, não questionam a forma de lidar com sua clientela.

Ao classificar posturas diversas de profissionais de saúde em relação a sua clientela, Angerami-Camon (1998) denomina "calosidade profissional" a um distanciamento do profissional de saúde, experiente, que já está "acostumado" com a dor e o sofrimento do outro, que se caracteriza pela assunção de uma posição de indiferença total em relação a estes aspectos. Como parte desta maneira de agir, cabe ao profissional relacionar-se apenas com a doença e se comprometer com a eficiência técnica,

Paidéia, FFCLRP-USP, Rib. Preto, junho/99. o que segundo o autor, trata-se de uma forma de defender-se contra o seu envolvimento com a dor do outro, protegendo-o do sofrimento que esta situação na maioria das vezes encerra.

Dentre as inúmeras condutas que encontramos no hospital, que lesam os direitos dos usuários, citaremos algumas e, através delas, poder-se-á deduzir que condutas favorecem a humanização e como se pode respeitar os direitos dos mesmos, além de discutir qual é a importância do trabalho interdisciplinar para evitá-las.

$\mathrm{O}$ afastamento da família durante a internação configura-se como a primeira e mais corriqueira forma de lesar a clientela, e tem sido um tema muito discutido atualmente, principalmente quando se trata de crianças.

A possibilidade de permanecer ao lado do familiar, em caso de crianças, é estabelecida por lei no Brasil $^{2}$, mas ainda assim existem hospitais que não cumprem esta determinação, sob a alegação de que famílias atrapalham as rotinas, são fonte de desordem e rebeldia, interferem no bom andamento dos serviços (Crepaldi, 1999).

Embora se aborde muito mais extensamente a inadequação do afastamento de familiares em caso de doentes que são crianças, os pacientes adultos são igualmente prejudicados quando permanecem sozinhos, pois o hospital encerra um contexto que lhes é pouco familiar, lugar de práticas desconhecidas e dolorosas. Os profissionais atendem a rotinas pesadas de trabalho, ocupando-se da intervenção técnica por excelência, como fazer um exame clínico, dar uma medicação, "pegar uma veia", "passar uma sonda", por exemplo, e assim têm pouco tempo para conversar, dar uma atenção personalizada à clientela, sem contar com o fato de que este tipo de atenção é considerado, geralmente, como uma forma de "enrolar o serviço".

Sem se falar no fato de que a doença provoca, muitas vezes, no sujeito, um sentimento de menos valia, a possibilidade de regressão, que experiencia por estar preso ao leito, dependente de cuidados de outrem, submetido às limitações provocadas pelos sintomas da doença e pelos efeitos da medicação, fatores que contribuem para comprometer emocionalmente o paciente, provocando sen-

\footnotetext{
${ }^{2}$ Lei 8069 de 13 de julho de 1990 - Esttuto da Criança e do Adolescente - artigo 12
} 
timentos de fragilidade e abandono.

A presença da família não deveria ser apenas uma concessão do hospital, mas deveria ser compulsória e os horários para visitas deveriam ser livres, já que nos hospitais particulares pode-se manter um acompanhante permanentemente junto da pessoa doente, que paga $o$ atendimento, sem que estes aspectos sejam questionados.

A família pode tornar-se um coadjuvante importante quando o hospital admite que participe e quando estiver bem orientada. Há trabalhos de pesquisa que mostram como a família pode participar, beneficiando-se da atenção recebida e fornecendo assistência para seu parente que está no hospital (Crepaldi, 1989, 1999).

A exposição e manipulação pública do corpo são outros aspectos pouco questionados no hospital.

Independentemente da idade da pessoa, seja adulto, criança, adolescente ou idoso, a exposição do corpo sem a privacidade devida é, sem dúvida, uma violação do espaço privado e íntimo dos doentes. Se o profissional está "acostumado a ver e manipular", como repete seguidamente para a clientela, as pessoas não estão acostumadas a mostrar, expor seus corpos publicamente. Esta prática encerra a banalização do corpo que deve ser alvo de intervenção, e embora a intenção seja a de "ajudar" o indivíduo a resgatar sua saúde, a forma de expô-lo é ainda muito aviltante e precisa ser questionada. Garantir o mínimo de privacidade nas enfermarias não é impossível, trata-se de uma preocupação ética, humana, que pode ser efetivada através de procedimentos simples.

Acontece também, com certa frequência, a infantilização do paciente adulto ou excessiva infantilização da criança.

A tendência dos que cuidam, mesmo que não o percebam, é aumentar o sentimento de dependência do doente, a medida em que o trata como uma criança, empregando palavras na forma diminutiva quando se dirigem a estes, como por exemplo: "vamos levantar desta caminha", "coloque seu bracinho aqui". Mesmo crianças pequenas, que já desfrutam de alguma autonomia não gostam deste tratamento, e devem ser respeitadas e incentivadas na sua capacidade de se auto governar.

Outra forma de submeter a clientela é não chamar as pessoas pelo nome, mas caracterizá-lo por atributos como o leito que ocupa, a doença que tem, ou denominações diversas que são utilizadas. Como exemplo deste fato tem-se nas enfermarias de pediatria, o hábito de uniformizar o chamamento da mãe pela sua função, ou seja, "mãe" ou "mãezinha".

O problema da memorização dos nomes pode ser minimizado com um sistema de placas que se pode colocar nos leitos indicando o nome da mãe, da criança, médico responsável, e o mesmo procedimento pode ser adotado para pacientes adultos.

Os apelidos que a equipe de saúde encontra para designar as pessoas quando estas se encontram em situações extremas como "SPP" (se parar parou), para referir-se à pacientes que estão na eminência de morte e que por decisão da equipe não deverão ser reanimados.

$O$ afastamento quase que absoluto da equipe quando o paciente está à morte. Neste caso a equipe restringe-se aos procedimentos absolutamente necessários para a consecução do seu trabalho.

Entende-se que ambas as condutas são mecanismos de defesa que a equipe utiliza para banalizar a dificuldade, no primeiro caso, e não entrar em contato com o seu proprio sofrimento, no segundo, tendo em vista a situação grave de difícil manejo e enfrentamento, mas que submetem as pessoas ainda mais à condição de objetos.

Por mais que se possa compreender o quão difícil é, para toda a equipe, lidar com a terminalidade, não se pode admitir este tipo de tratamento. Por outro lado, pode-se pensar em formas mais humanas, respeitosas e, portanto, adequadas para se lidar com este doente.

Outra questão fundamental é a veiculação da informação no ambiente hospitalar.

O paciente e sua família nem sempre são informados sobre o que vai ocorrer no hospital, sem contar que em muitas ocasiões o doente não é consultado sobre se aceita ou não ser submetido a certos procedimentos, ou que sua família possa decidir por ele quando está impossibilitado de fazê-lo.

Assim, o paciente tem direito a obter informações precisas ${ }^{3}$, quando estas estão disponíveis, sobre sua doença, as dimensões e implicações das terapêuticas a que será submetido, como o uso de medicação, de dispositivos médicos de alta

\footnotetext{
${ }^{3}$ Portaria no 41 do Ministério da Justiça
}

Paidéia, FFCLRP-USP, Rib. Preto, junho/99. 
tecnologia, ter informações sobre exames necessários, e ser dispensado de exames desnecessários. Além de ser consultado sobre se deseja ou não ser submetido a estes procedimentos.

Há implicações importantes para os usuários quando as formas de comunicação de diagnóstico nos casos de doenças graves, de prognóstico reservado, e de terapêuticas de diversos tipos, por exemplo, não são adequadas. A informação de um diagnóstico desta natureza envolve outras dimensões da vida de uma pessoa, como refere AngeramiCamon (1998), não é apenas uma comunicação de que esta tem uma determinada doença, mas envolve a princípio uma reação emocional do paciente, de sua família. Pode haver conseqüências para a família, como a desestruturação familiar, separação de cônjuges; além de conseqüências sociais como perda de um emprego, mudança de cidade, entre outras.

Além da informação sobre o diagnóstico, é comum que se ouça que o paciente não assimila a informação, porque não entende, não tem "nível cultural" para tanto, quando na realidade, não existe disponibilidade de quem atende para traduzir a linguagem médica e eminentemente hospitalar, para que os usuários possam compreender. Sem contar que o universo sócio-cultural dos sujeitos também não é um interesse que esteja presente no cotidiano das equipes de saúde. A visão de quem atende é por assim dizer etnocêntrica, na medida em que a alteridade dos usuários não é aspecto relevante, ou seja, o paciente e sua família é que devem adequar-se ao universo hospitalar.

As perguntas que estas constatações suscitam são sempre da mesma ordem, ou seja: como fazer para mudar esse estado de coisas? Como preservar a ética e a eficácia técnica na assistência a um só tempo? Como tornar o tratamento mais humano sem envolver-se a ponto de "confundir-se" com outro, e vir a sofrer juntamente com ele?

\section{A interdisciplinaridade}

Em primeiro lugar é necessário pensar como os profissionais desumanizam-se mutuamente no cotidiano do hospital, sem que tenham consciência de seus atos, antes mesmo de se falar em desumanização do atendimento. A começar pelas relações hierarquizadas e assimétricas que a realidade institucional thes impõe. As rotinas de trabalho que muitas vezes submetem o profissional a turnos pesados. $\mathrm{O}$ acúmulo de mais de um emprego devido aos baixos salários, além de problemas nas relações de trabalho decorrentes, muitas vezes, da falta de solidariedade, de apoio mútuo em situações de difícil manejo e enfrentamento, além do despreparo da equipe para atuar no âmbito da interdisciplinaridade.

O trabalho interdisciplinar é uma alternativa importante para resolver não apenas os problemas da assistência, mas também os problemas que ocorrem no âmbito das relações interprofissionais.

A medida em que cada profissional tornase consciente de que não pode, por motivos técnicos ou pessoais, enfrentar certos obstáculos por si só, e para isto solicita a ajuda da equipe de trabalho, que por sua vez se dispõe a tomar a resolução do problema como uma tarefa de equipe, tem-se o exercício da interdisciplinaridade, mesmo que a solução do problema não esteja clara, a priori.

Como exemplo pode-se tomar a comunicação do diagnóstico em situações de doenças de risco. Acredita-se que por sua competência técnica é sempre o médico que deve exercer a função de comunicar o diagnóstico. Nem sempre, porém, essa competência técnica lhe confere condições emocionais para fazê-lo. Neste caso a ajuda da equipe é imprescindível, o profissional mais indicado para a tarefa deveria ser aquele que se sente mais "à vontade", seja por sua proximidade com o paciente e sua família, seja por empatia para com eles, ou por outros motivos que a equipe pode discutir. A equipe pode decidir sobre quem vai dar o diagnóstico, ou que grupo de pessoas da equipe poderá fazê-lo, já que não é prerrogativa de uma única pessoa. $O$ fato de o médico não estar presente não inviabiliza um contato com ele, para obtenção de maiores informações, e os profissionais escolhidos podem se dispor a acompanhar o paciente a presença do médico para obter informações mais específicas, desde que este se disponha a dar as informações, apoiado por outros profissionais.

Enfim, esta deveria ser uma decisão do conjunto das pessoas que compõem a equipe de saúde.

Assim a interdisciplinaridade configura-se como um motivo poderoso que a equipe de saúde 
possui para o manejo de situaą̧̃̃es desde as mais simples até as mais polêmicas, promovendo assim um atendimento mais ético e eficaz, mas na maioria das vezes esta não sabe utilizar.

Em um trabalho de pesquisa realizado no Instituto da Criança do Hospital das Clínicas da Faculdade de Medicina da USP, pudemos mostrar como uma equipe de saúde, através de procedimentos simples, mantinha um intercâmbio permanente, sem que tivesse para isto, necessariamente, hora e local estabelecido para efetuar trocas. Tais trocas tinham como tema tanto aspectos técnicos e relativos às rotinas e serviços como aspectos de ordem pessoal de profissionais e usuários que poderiam ter importância para a equipe, e tornavam-se fundamentais para incrementar e enriquecer a assistência (Crepaldi, 1999).

A medida que cada profissional pode considerar-se apoiado pelo colega, no sentido técnico e humano, através de trocas de experiências, saberes, procedimentos, modos de lidar com o sofrimento, com o que despersonaliza e submete o outro, quer seja este, colega ou paciente, pode-se modificar esse estado de coisas. Para tanto é importante partir-se da constatação de que cada um individualmente não está preparado para lidar com a complexidade que a realidade hospitalar encerra.

\section{Referências Bibliográficas}

Angerami-Camon, V. A. (1998). Breve reflexão sobre a postura do profissional da saúde diante da doença e do doente. Em V. A. AngeramiCamon (Org.), Urgências Psicológicas no Hospital (pp. 41-60). São Paulo: Pioneira.

Berlinguer, G. (1996). A Ética da Saúde. São Paulo: Hucitec

Foucault, M. (1985). Microfísica do poder. Rio de Janeiro: Graal Editores

Pitta, A. (1999).Hospital: dor e morte como oficio. São Paulo: Hucitec

Goffman, E. (1961). Asylums, essays on the social situation of mental patients and other inmates, New York: Doubleday and Co.

Crepaldi, M. A. (1989). Hospitalização Infantil: es- tudo das interações família-equipe hospitalar. Dissertação de Mestrado, PUC-RJ, Rio de Janeiro.

Crepaldi, M. A. (1999). Hospitalização na Infância: representações sociais da familia sobre a doença e hospitalização de seus filhos. Taubaté: Cabral Editora Universitária. 